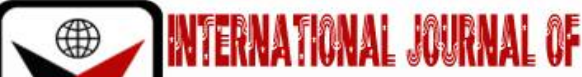

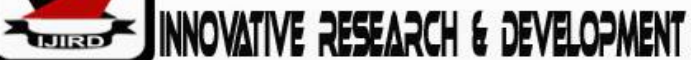

ISSN 2278-0211 (Online)

\section{Interpersonal Relationship and Staff Development Programmes as Indices of Job Satisfaction among the Service Providers of Oyo State Sports Council (OYSSC), Nigeria}

\author{
Dr. Ezomoh Olusoga Olumide \\ Senior Lecturer, Department of Human Kinetics and Health Education, \\ University of Portharcourt, Nigeria \\ Dr. Adisa Olawumi \\ Lecturer, Department of Human Kinetics and Health Education, \\ University of Ibadan, Nigeria
}

\begin{abstract}
:
The purpose of this study was to find out if interpersonal relationship and staff development programmes were indices of job satisfaction among the service providers of Oyo State Sports Council (OYSSC). For the purpose of this study, two research hypotheses were proposed. The study was delimited to the entire service providers of OYSSC, the independent variables of interpersonal relationship and staff development programmes, dependent variable of job satisfaction, descriptive survey research design, self-developed, validated and closed-ended modified Likert type questionnaire as the only instrument for data collection, judgmental sampling technique and 4- trained and tested research assistants who were employed to administer the instrument to, and retrieve them from the respondents. The inferential statistics of chisquare $\left(X^{2}\right)$, set at 0.05 confidence level was used to test the hypotheses under study. Consequent upon the findings of this study, it was therefore concluded that; interpersonal relationship and staff development were indices of job satisfaction among the service providers of OYSSC. Sequel to the findings, it was therefore recommended among others that; OYSSC sports council management should encourage the development of close and mutually satisfying relationship among the staff, continue to allow the staff to work as a group or team in a desired direction towards achieving the establishment's goals, continue to provide means for staff professional skills development and provide more training opportunities for their staff to develop as professionals.
\end{abstract}

Keywords: Interpersonal relationship, staff development programmes, job satisfaction, service providers

\section{Introduction}

Sport is one area of endeavour that cuts across various barriers, such as; age, sex, race, creed, economic status, among others. But one salient point is that those who participate in sports do so because of the expected gains or reward, whether intrinsic or extrinsic. This means that rewards expected by people could be good health, enjoyment, fun (intrinsic) or money, scholarship, promotion etc. (external)(Fadoju, 2003).

Loy (2016); Nixon and Jewett (2009), agreed that sport is such a pervasive social phenomenon introduced on all aspects of daily life. Sport is an integral part of the society through which useful values and aspirations of the society are passed from generation to generation; sport in many ways contributes immensely to socializing young ones, even at the remotest parts of the country into major cultural, social and behavioural patterns of the society in which they live. Sporting activities have been from immemorial and are as old as man himself and are part of life in our contemporary society. Human beings both young and old have been involved in sporting activities either as organized sports or unorganized sports.

Generally, sport concept is not precisely defined, as the concept of sports and games are mostly used interchangeably. Sport can be regarded as an institution and social system with far reaching effects for human beings in many social contexts, such as; sociological, psychological, political, economical and to mention just a few. According to Bucher (2009), sport again is an institutionalized competitive activity, which involves strenuous exertion or put differently, the use of relatively complex physical skills by the individual whose participation may be motivated. As it is thus regarded as a social institution that faithfully teaches and reinforces societal values, thereby contributing to socializing athletes into major cultural, social and behavioural patterns of the society.

According to Grimes (2011), the idea or organized sports came into existence with the advent of Greek civilization. Since then organized sports were seen by some as contests in which individuals compete against individuals, while others view them as political contests in which the honour of one nation is pitched against that of another. 
Job satisfaction refers to the amount of overall positive effect or feeling that staff or service providers have towards their jobs. Most sports administrators and sports service providers of management cadre are employees. Many sports administrators/sports managers feel morally responsible for maintaining a high level of job satisfaction in their sports organizations. However, whether sport service providers find their jobs satisfying or frustrating, challenging or boring, meaningful or pointless is a strong concern for sports administrators/sports managers that they are concerned about the impact which job satisfaction has on performance. Most sports managers or sports administrators believe that job dissatisfaction leads to low productivity, high absenteeism, low turnover and increased unionization(Ezomoh \& Amasiatu, 2012).

Job satisfaction is the degree to which an individual feels positive about the various aspects of job tasks, the work setting and the relationship with co-workers (Baridam, 2009). The happier people feel within their job, the more satisfied they are said to be.Job satisfaction, according to Abdullah (2017) is an important element influencing firms' performance. A high level of job satisfaction produces positive attitude towards job performance, which in turn can reduce the level of absenteeism, termination of service, negligence at work and increase the efforts of service providers towards work excellence and productivity. Cherrington (2014) postulated that high job satisfaction of employees contributes to organizational commitment, job involvement, improves physical and mental health as well as improves quality of worker's life both on, and off the job. Both negative and positive factors can lead to job satisfaction or dissatisfaction. Social issues such as struggles with nonspecific or difficult individuals and social defeat, or relationship conflicts can cause job satisfaction or dissatisfaction.

Sports participation is all over the world. When talking about sports, people think more about athletes and spectators as producers and consumers or as active and passive participants without regards to those who make frantic efforts to ensure that these activities take place, those who make sure that the required facilities and equipment are adequately available and well maintained, those who protect the facilities and equipment, those who make efforts to see that funds are available for organizing interesting sporting activities, just to mention a few. These are the sports council's service providers.

Consequent upon the above statements, it is highly essential for employers of labour or administrators to ensure that their service providers have job satisfaction. Suffice it to say, however, that some employers or administrators want their service providers to have job satisfaction, but they do not know how to go about it. This simply implies that, first and foremost, it is important to know the indices or variables of job satisfaction that will work well before thinking of how to apply them.

In the light of the above, the researchers considered it very imminent to attempt to find out if interpersonal relationship and staff development programmes were indices of job satisfaction among the service providers of Oyo State Sports Council (OYSSC).This study was delimited to the entire service providers of OYSSC. The study aimed to provide a better understanding to sports administrators and managers on the effective indices of job satisfaction among sport service providers in sports establishments. It is also envisaged that this study may add to the corpus of existing knowledge and provide a spring board to generate further studies on job satisfaction and sports administration, as well as act as a references point for further research works in the field of sports administration.

Oyo State is one of the states in the south western part of Nigeria, created out of the former Western State of Nigeria on February 3, 1976. It is located within latitudes 70 and $9010^{\prime} \mathrm{N}$, and longitudes $2040^{\prime}$ and 40 35'E with a total land mass of 28,249 square kilometers and population of 5,591,589 according to 2006 census. It is bounded in the north by Kwara State, in the east by Osun State, in the south by Ogun State and in the west partly by Ogun State and partly by the Republic of Benin. The state is inhabited mainly by people of the Yoruba ethnic group. Ibadan, the state capital is the largest indigenous city in sub-Saharan Africa. The state has thirty-three (33) Local Government Areas (LGAs). Oyo state sport council came into being with the enactment of the Western Region Law No. 51, of 1959, which was subsequently amended with Law No. 6 of 1964. The edict that established 'Sports Council' as it is now was signed into Law on 1 st July, 1976 which was also amended in August 1982 and June, 1999 respectively

\section{Methodology}

The descriptive survey research design was used for the study. The population for the study comprised all the service providers of the Oyo State Sports Council. A sample size of 6320yo State Sports Council service providers was used for the study. The judgmental sampling technique was use to select all the 632 sport services providers in the OYSSC. Aself-developed modified Likert type questionnaire, with a reliability index of 0.89 was used for the study, while the inferential statistics of chi-square $\left(\mathrm{X}^{2}\right)$, set at .05 alpha level was used to test the hypotheses under study.

\section{Data Analysis, Interpretation and Discussion of Findings}

- Hypothesis 1: Interpersonal relationship will not be a significant index of job satisfaction among the service providers of OYSSC.

\begin{tabular}{|c|c|c|c|c|c|}
\hline Variable & Cal X'cal & t-value & Df & P-value & Decision \\
\hline $\begin{array}{c}\text { Interpersonal } \\
\text { relationship }\end{array}$ & 276.23 & 12.59 & 6 & .05 & Rejected \\
\hline
\end{tabular}

Table 1: Chi-Square Analysis of Interpersonal Relationship and Job Satisfaction among the Service Providers of OYSSC (N=632) 
Table 1 above, shows that interpersonal relationship has a calculated $\mathrm{X}^{2}$ value of 276.23 , a table value of 12.59 , at degree of freedom 6 , and alpha level .05, which made the hypothesis to be rejected. Therefore it means that interpersonal relationship is a significant index of job satisfaction among the service providers of OYSSC.

This finding suggests that sports service providers are concerned with their relationship with colleagues for both personal comfort and facilitating job. They prefer physical surroundings that are not dangerous or uncomfortable. Some even prefer working relatively with modern facilities and adequate tools and equipment. Friendly and supportive coworkers lead to increase in job satisfaction. Also, if one's immediate supervisor understands, and is friendly, it also leads to increase in job satisfaction.

In line with this finding, Herzberg (2019), listed 10 hygiene factors in sports profession to include; sports council policy and administration, supervision, interpersonal relations with supervisors, interpersonal relation with peers/colleagues and interpersonal relation with subordinates. Others are; working conditions, salary, personal life, status and job security

- Hypothesis 2: Staff development programme will not be a significant index of job satisfaction among the service providers of OYSSC.

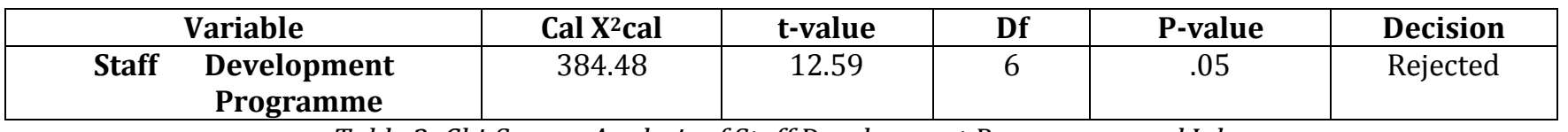

Table 2: Chi-Square Analysis of Staff Development Programme and Job

Satisfaction among the Service Providers of OYSSC (N-632)

Table 2 shows a $\mathrm{X}^{2}$ calculated value of 384.48, a table value of 12.59 at 6 degrees of freedom and an alpha level of .05. Since the chi-square decision rule says if the calculated chi-square value is greater than the critical table value, the hypothesis should be rejected. Therefore, the above hypothesis is hereby rejected.

The finding of this study buttresses that of McMuller (2011), who discovered that staff development programme is a planned process of development which enhances the quality of job performance by identifying, clarifying and meeting the individual needs of the staff within the context of the sports as a whole. Staff development should relate to the individual, the interested groups and the whole sports. Its primary aim should be to increase the quality of work done through the development of staff potential and should thus seek to recognize the specialized needs of the individual administrator or line manager.

Hewton, (2018), however, stated that, the effectiveness of organizations depends upon the quality of life provided for those working with in them. Ferrister-Macher and Berlinger (2015) maintained that staff development has become an activity that encompasses much more than a single service provider as individuals, it is understood that this person's activities are part of the larger environment of the sports.

Hewton and Bradley (2013) pointed out that if the quality of staff development will be greatly enhanced in a sport where service providers are; they should be:

- Encouraged to plan and evaluate their work jointly with colleagues.

- Involved in visits to other sports council and other sports facilities.

- Encouraged to attend courses.

- Encouraged to keep to date on specific sport rules and educational developments in general).

- Able to participate in seminars, workshops, symposium, both sports-based and externally.

- Encouraged to study and question their own practice

- Involved in management decisions.

Hewton (2018) stated that to encourage staff to be actively involved in their own development, a head of unit needs to be able to identify what motivates the staff to optimal performance, to find ways to positively influence these motivating factors, and to know how the sports organization can maximize them.

\section{Summary, Conclusion and Recommendations}

\subsection{Summary}

The purpose of this study was to find out if interpersonal relationship and staff development programmes were indices of job satisfaction among the service providers of Oyo State Sports Council (OYSSC). For the purpose of this study, two research hypotheses were proposed. The study was delimited to the entire service providers of OYSSC. The independent variables of interpersonal relationship and staff development programmes, dependent variable of job satisfaction, descriptive survey research design, self-developed, validated and closed ended modified Likert type questionnaire as the only instrument for data collection, judgmental sampling technique, 4- trained and tested research assistants were employed to administer the instrument to, and retrieve them from the respondents, the inferential statistics of chi-square $\left(\mathrm{X}^{2}\right)$, set at 0.05 confidence level was used to test the hypotheses under study.

\subsection{Conclusion}

Consequent upon the findings of this study, it was therefore concluded that;

- Interpersonal relationship is a powerful index of job satisfaction among the service providers of OYSSC.

- Staff development is an inevitable index of job satisfaction among the service providers of OYSSC. 


\subsection{Recommendations}

Sequel to the findings of this study, the following recommendations are made:-

- $\quad$ OYSSC sports council management should encourage the development of close and mutually satisfying relationship among the staff.

- $\quad$ The OYSSC sports council management should continue to allow the staff to work as a group or team in a desired direction, towards achieving the establishment's goal.

- The OYSSC sports council management should continue to provide means for staff professional skills development.

- $\quad$ The OYSSC council management should provide more training opportunities for their staff to develop as professionals.

- $\quad$ The OYSSC council management should not frown at any staff that is pursuing educational or developmental programmes.

\section{References}

i. $\quad$ Abdullah, P. (2017). Sport and culture. Journal of Sport Sciences. 5 (3) 90-97.

ii. Baridam, B.W. (2009). Developing sports in modern Nigeria. An overview of problems and prospects. In C.O. Udoh, A.S. Sohi and J.A Ajala (Eds) Organization of sports in Nigeria University. Proceedings of Nigeria Defence Academy Sports Clinic. Kaduna.

iii. Bucher, C.A (2009).Sport administration. St. Louis Missouri: C.V Mosby.

iv. Cherrinton, B. (2014). Effective sport organisation and administration. New York; Pluto

v. Ezomoh, 0. 0. \&Amasiatu, A. N. (2012), Evaluative analyses of leadership styles and staff appraisals as correlates of job satisfaction among sports service providers in the National Sports Federation of Nigeria. American Journal of Ecology (AJE)1 (4) 32- 44.

vi. Ferrister, C. \&Berlinger, V. (2015).F.E. inc-business orientation in Everard, B. \& Morris, G. (1990).Effective Sport Management. A Mechanism for Development, London: Falmer.

vii. Grimmes, A. (2011). The constitution of society.Cambridge; Polity.

viii. Hewton, J. \&Bradley, C. (2013). Grassrootsport administration.London; Routledge.

ix. Heizberg, E. (2019). School focused staff development, London; Falmer.

x. Hewton, P. (2018). Dictionary of social sciences. London; Henley and Boston.

xi. Loy, J.W (2016).Sports culture and society.A reader on the sociology of sports. London: The Macmillan.

xii. McCmuller, M. (2011, August 18). Mark of authority.To Golf Monthly Correspondents (Interviewer). The Bullet, 17.70-71.

xiii. Nixon, J.\& Jewett, B. (2009). Appraisal at the crossroads, Management in Education, Second edition, London: Paul Chapman. 